\title{
Sunlight exposure or vitamin D supplementation for vitamin D-deficient non-western immigrants: a randomized clinical trial
}

\author{
I. S. Wicherts • A. J. P. Boeke • I. M. van der Meer • \\ N. M. van Schoor • D. L. Knol • P. Lips
}

Received: 23 December 2009 / Accepted: 17 June 2010 / Published online: 4 August 2010

(C) The Author(s) 2010. This article is published with open access at Springerlink.com

\begin{abstract}
Summary Vitamin D deficiency is very common in nonwestern immigrants. In this randomized clinical trial, vitamin D $800 \mathrm{IU} /$ day or $100,000 \mathrm{IU} / 3$ months were compared with advised sunlight exposure. Vitamin D supplementation was more effective than advised sunlight exposure in improving vitamin D status and lowering parathyroid hormone levels.
\end{abstract}

\footnotetext{
I. S. Wicherts $\cdot$ A. J. P. Boeke $\cdot$ N. M. van Schoor $\cdot$ P. Lips EMGO Institute for Health and Care Research,

VU University Medical Center,

Amsterdam, The Netherlands

I. S. Wicherts

School of Health Care,

Windesheim,

Zwolle, The Netherlands

\section{A. J. P. Boeke}

Department of General Practice, EMG0 Institute for Health and Care Research, VU University Medical Center,

Amsterdam, The Netherlands

I. M. van der Meer

Municipal Health Service of The Hague,

The Hague, The Netherlands

\section{L. Knol}

Department of Clinical Epidemiology and Biostatistics,

VU University Medical Center,

Amsterdam, The Netherlands

\section{P. Lips $(\bowtie)$}

Endocrine section, department of Internal Medicine,

VU University Medical Center,

P.O. Box 7057, 1007 MB Amsterdam, The Netherlands

e-mail: P.Lips@vumc.nl
}

Introduction Vitamin D deficiency (25-hydroxyvitamin D $[25(\mathrm{OH}) \mathrm{D}]<25 \mathrm{nmol} / \mathrm{l})$ is common among non-western immigrants. It can be treated with vitamin D supplementation or sunlight exposure.

Methods To determine whether the effect of vitamin $\mathrm{D}_{3}$ supplementation (daily $800 \mathrm{IU}$ or $100,000 \mathrm{IU} / 3$ months) or sunlight exposure advice is similar with regard to serum $25(\mathrm{OH}) \mathrm{D}$ and parathyroid hormone $(\mathrm{PTH})$ concentrations. Randomized clinical trial in 11 general practices in The Netherlands. Non-western immigrants, aged 18-65 years $(n=232)$ and serum $25(\mathrm{OH}) \mathrm{D}<25 \mathrm{nmol} / 1$ were randomly assigned to supplementation (daily $800 \mathrm{IU}$ or $100,000 \mathrm{IU} /$ 3 months) or advice for sunlight exposure for 6 months (March-September). Blood samples were collected at baseline, during treatment (3 months, 6 months), and at follow-up (12 months). Statistical analysis was performed with multilevel regression modelling.

Results The intention-to-treat analysis included 211 persons. Baseline serum 25(OH)D was $22.5 \pm 11.1 \mathrm{nmol} / 1$. After 6 months, mean serum 25(OH)D increased to $53 \mathrm{nmol} / 1$ with $800 \mathrm{IU} /$ day, to $50.5 \mathrm{nmol} / 1$ with $100,000 \mathrm{IU} / 3$ months, and to $29.1 \mathrm{nmol} / 1$ with advised sunlight exposure (supplementation vs sunshine $p<0.001$ ). Serum PTH decreased significantly in all groups after 3 months, more in the supplementation groups than in the advised sunlight group $(p<0.05)$. There was no significant effect on physical performance and functional limitations.

Conclusion Vitamin D supplementation is more effective than advised sunlight exposure for treating vitamin D deficiency in non-western immigrants.

Keywords Non-western immigrants · RCT vitamin D . Secondary hyperparathyroidism $\cdot$ Sunlight exposure . Vitamin D deficiency - Vitamin D supplementation 


\section{Introduction}

Vitamin D deficiency is common among moderately and heavily pigmented immigrants living in Europe [1-6] and other continents. Recent studies in the Netherlands have shown that $40 \%$ to $80 \%$ of non-western immigrants are vitamin D-deficient (serum 25-hydroxyvitamin D, 25(OH) $\mathrm{D}<25 \mathrm{nmol} / \mathrm{l}$ ) [7-9]. Approximately 1.7 million nonwestern immigrants are currently living in the Netherlands (http://statline.cbs.nl/StatWeb/start.asp, accessed 12 March 2008), suggesting that at least 680,000 of these immigrants are vitamin D-deficient.

During exposure to sunshine, UV photons (290-315 nm) penetrate the epidermis and photolyse 7-dehydrocholesterol (provitamin $\mathrm{D}_{3}$ ) to previtamin $\mathrm{D}_{3}$. Melanin effectively filters the UV radiation that enters the epidermis and limits the synthesis of vitamin $\mathrm{D}_{3}$ [10]. The more melanin there is in the skin, the lower the amount of previtamin $\mathrm{D}_{3}$ that is synthesized by a given dose of UVB. In heavily pigmented individuals, only a fraction of the available UVB reaches the 7-dehydrocholesterol in cells for vitamin $\mathrm{D}_{3}$ synthesis [11]. Besides skin type, low sunshine exposure, covering of the skin, use of sunscreens, aging, and low dietary vitamin $\mathrm{D}$ and calcium intake contribute to a deficient vitamin D status [12]. The fact that, in the Netherlands, only margarine, which is not regularly consumed by nonwestern immigrants, is fortified with vitamin D (3 IU per gram) also adds to the risk for developing vitamin $\mathrm{D}$ deficiency.

Vitamin D deficiency initially causes an increase of the serum parathyroid hormone (PTH) concentration [1], which results in bone loss, followed by a defective mineralization of the newly formed bone (the osteoid tissue), resulting in osteomalacia in the long term [5, 12, 13]. However, the degree of PTH increase may be very different, from almost none to frank secondary hyperparathyroidism. With regard to musculoskeletal health, studies have shown that poor vitamin D status (low serum $25(\mathrm{OH}) \mathrm{D})$ is associated with poor physical performance [14-21], weakness of the proximal muscles [22], and pain [23], but other studies did not find this association [24, 25]. Several clinical trials have demonstrated that vitamin D supplementation can decrease fracture risk $[12,16]$

Vitamin D deficiency can be treated by sunshine exposure or vitamin D supplementation, either daily or with greater intervals such as monthly or every 3 months. However, within non-western immigrants, the efficacy of those interventions on both vitamin D status and clinical outcomes has never been compared. Social and cultural habits may hamper exposure to sunshine in some groups of immigrants. Compliance is another issue that should be addressed.
The principal aim of this study was to determine whether the effects of supplementation with vitamin $\mathrm{D}_{3}$ (daily $800 \mathrm{IU}$ or $100,000 \mathrm{IU} / 3$ months) or advised sunlight exposure are similar with regard to serum $25(\mathrm{OH}) \mathrm{D}, \mathrm{PTH}$, and alkaline phosphatase concentrations. The second aim was to investigate whether the effects of the different interventions are comparable with respect to three clinical outcomes: physical performance tests, functional limitations, and pain.

\section{Methods}

Study design and setting

The study was designed as a randomized controlled trial, comparing the effect of supplementation with vitamin $\mathrm{D}_{3}$, either a daily dose or an equivalent dose once every 3 months, with the effect of advice for sunlight exposure. The active study treatment was administered during 6 months, between March and September, as these are the months where sunlight results in vitamin D synthesis in the skin at the latitude of the Netherlands $\left(52^{\circ} \mathrm{N}\right)$. Data and blood samples were collected at baseline, during treatment (at 3 months and 6 months), and during the follow-up period (at 12 months). After eligibility was verified, written informed consent was obtained. The study was approved by the Medical Ethics Committee of the VU University Medical Center. The trial has been registered at the Dutch Clinical Trials Register (NRT; ISRCTN58849315, http://www.trialregister.nl).

\section{Study participants}

Participants were non-western immigrants aged 18-65 years with documented vitamin D deficiency (serum 25-OHD< $25 \mathrm{nmol} / \mathrm{l}$, according to analysis made by local laboratory) within 3 months before the start of the study. Participants were recruited from 10 collaborating general practices (GPs) (Amsterdam, The Hague, Haarlem, Amersfoort) and one university clinic (Amsterdam) in The Netherlands. Participants were recruited between January and March 2004 and between January and March 2005 by their general practitioners. Participants were invited at their local GPs or the university clinic during the study for the assessments and blood sampling. We anticipated a high risk to lose participants during the study if they had to travel to the hospital. Potential participants were excluded if they (a) had been treated for vitamin D deficiency within the last 3 months, (b) were immobile, or (c) had diseases interfering with measurements (e.g., psychiatric disorders, rheumatoid arthritis). Research nurses and GP 
assistants received a central training regarding randomization, medication, and measurements.

\section{Treatment}

An independent statistician, not involved in recruitment of patients, generated a random list that was stratified for general practitioner and sex by permutation of randomized blocks, with a block size of 6 . A researcher opened prepared, numbered, opaque, sealed envelopes containing the treatment codes. The participants were randomized into three groups: advice for direct sunlight exposure for at least one half hour per day, vitamin $\mathrm{D}_{3} 800 \mathrm{IU} /$ day (two tablets of $400 \mathrm{IU}$ ), or vitamin $\mathrm{D}_{3} 100,000 \mathrm{IU}$ once in 3 months (four capsules of 25,000 IU). The participants in the sunlight group had to keep a diary on sunlight exposure.

Participants in the $800 \mathrm{IU}$ group had to return the supplement bottle at the next appointment, and participants of the 100,000 IU group took the vitamin D under supervision. The vitamin $\mathrm{D}_{3}$ was provided for 6 months, as long as the sunlight is effective in the Netherlands, i.e., the end of September. The high-dose vitamin $\mathrm{D}_{3}$ group received 100,000 IU at baseline and at 3 months.

\section{Outcomes}

Primary outcomes: biochemistry

Blood samples were obtained at baseline (in fasting state), 3 months, 6 months (in fasting state), and 12 months. The blood was immediately centrifuged and the plasma or serum was used immediately or frozen for later measurements. Serum calcium, phosphate, albumin, creatinine, and alkaline phosphatase were measured according to routine laboratory methods in a local laboratory. For serum $25(\mathrm{OH}) \mathrm{D}$ and $\mathrm{PTH}$, serum was kept frozen at $-20^{\circ} \mathrm{C}$ until analysis at the university laboratory. All samples from one person were analyzed in the same run in order to minimize variation. Serum 25 $(\mathrm{OH}) \mathrm{D}$ was analyzed using radioimmunoassay (Diasorin, Stillwater, MN, USA). The intra-assay coefficient of variation was $12 \%, 9 \%$, and $7 \%$ for, respectively, 8,25 , and $100 \mathrm{nmol} / \mathrm{l}$. The inter-assay coefficient of variation was $20 \%, 10 \%$, and $8 \%$ for, respectively, 8,30 , and $65 \mathrm{nmol} / \mathrm{l}$. The lower detection limit of the assay was $5 \mathrm{nmol} / \mathrm{l}$. Serum PTH was analyzed using immunoradiometricassay (Luminescence, Immulite 2500, DPC, Los Angeles, CA, USA). The intra-assay coefficient of variation was $3 \%$ for the $0.3-20 \mathrm{pmol} / 1$ range, and $4 \%$ for $>20 \mathrm{pmol} / 1$. The inter-assay coefficient of variation was $7 \%$ of the total range. The lower detection limit of the assay was $0.3 \mathrm{pmol} / \mathrm{l}$.
Clinical outcomes

Both physical performance tests to measure muscle strength and questionnaires to assess functional limitations in daily activities and pain were used.

\section{Physical performance tests}

These tests were done according to the manual of the Longitudinal Aging Study Amsterdam (LASA), and the scores relate to falls and fractures [26]. Handgrip strength was used as an indicator of muscle strength $(\mathrm{kg})$ and was assessed using a hand grip strength dynamometer (Takei TKK 5001, Takei Scientific Instruments, Tokyo, Japan). Subjects stood with arms and wrists stretched out at the sides of the body. They were asked to perform two maximum force trials with each hand. For the final scores, the maximum value, whether left or right hand, was used. The inter-observer coefficient of variation was $5 \%$. Secondly, chair stands test was used as an indicator of proximal muscle strength. To test the ability to rise from a chair, persons were asked to fold their arms across their chest and to stand up and sit down five times from a standard kitchen chair. Time taken to perform the task was measured (seconds).

\section{Functional limitations}

Functional limitations were assessed with a questionnaire concerning the degree of difficulty of the following three activities of daily living: getting up from a chair, climbing the stairs, and walking several hundred meters. In these daily activities, the muscles of the upper legs are addressed in particular. The scores per activity ranged from 0 (without difficulty) to 4 (help is needed). Both summed scores $(0-12)$ and dichotomized scores $(0=$ without difficulty or little difficulty, $1=$ great difficulty or help needed) were analyzed. These questions were adapted from the Longitudinal Aging Study Amsterdam [27] and were used in a prior survey in the Netherlands among non-western immigrants [8].

Pain

Six questions were asked to assess pain. To assess proximal muscle pain, the following two questions were asked: "Do you have muscle pain in your upper legs, while walking a small distance?" and "Do you have muscle pain in your upper legs, while sitting on a chair?" Scores were dichotomized into 0 "no pain" and 1 "yes" (sometimes or always). Participants were asked if they had shoulder pain during the last 2 weeks and how often they experienced shoulder pain per month. Participants were also asked if 
they experienced headaches during the last 2 weeks and the average number of headache episodes a year.

Potential confounders

The potential confounders, gender, age (at baseline), body mass index (BMI), and time of sunshine exposure (selfreported minutes per week) were included into the statistical analyses. Age was measured at baseline. BMI was calculated as weight $(\mathrm{kg}) /$ height $\left(\mathrm{m}^{2}\right)$. Body weight was measured without heavy clothes (e.g., jacket, coat) and shoes, using a calibrated balance beam scale. Body height was measured with a stadiometer, without shoes. BMI was categorized into three groups: underweight $(\mathrm{BMI}<20 \mathrm{~kg} /$ $\mathrm{m}^{2}$ ), normal weight $\left(20 \mathrm{~kg} / \mathrm{m}^{2} \leq \mathrm{BMI}<25 \mathrm{~kg} / \mathrm{m}^{2}\right)$, and overweight $\left(\mathrm{BMI} \geq 25 \mathrm{~kg} / \mathrm{m}^{2}\right)$. Information on sunlight exposure was based on self-report. To estimate the daily sunlight exposure, the respondents were asked to indicate time of day (before $12 \mathrm{am}, 12-15 \mathrm{pm}, 15-18 \mathrm{pm}$, and after $18 \mathrm{pm}$ ) and time (minutes) spent outdoors during summer months on weekdays and weekend days, respectively. Respondents were also asked to indicate areas of uncovered skin (face, hands, forearms, upper arms, lower legs, upper legs, upper abdomen, and back) during summer months on weekdays and weekend days.

\section{Statistical analysis}

Differences in demographic and baseline variables may occur by chance in a randomized study design. The three intervention-groups were first compared on these variables. Second, data analyses were performed based on treatment assignment according to the intention-to-treat principle. Longitudinal changes were investigated using the multilevel program MLwiN 2.02 [28-30]. Linear regression was used to investigate changes in serum 25 $(\mathrm{OH}) \mathrm{D}$ and $\mathrm{PTH}$, physical functioning, and functional limitations. The interaction between intervention and BMI was tested in the relationship between intervention and change in serum $25(\mathrm{OH}) \mathrm{D}$ by general linear models (interaction present if $p$ value $<0.10$ ). Logistic regression was used for investigating changes in pain in upper legs and functional limitations (dichotomized). MLwiN multilevel modelling is an extension of multiple regression, which is appropriate for analyzing hierarchically structured data. In the present longitudinal data set, a three-level hierarchy was defined, with the repeated measurements (defined as level-1 units) grouped within the individuals (who form the level-2 units), who were grouped within GPs (level 3 units). An advantage of using multilevel regression modelling compared to the traditional repeated measurement approach is that the number of measurements can vary between participants [29]. Additionally, differences between GPs can be modelled by a multilevel structure. A multilevel model describes not only underlying population trends in a response (the fixed part of the model), but also models the variation around this mean response due to the time of measurement and due to individual differences (the random part) [30]. Because some participants changed vitamin D status after screening, and were no longer vitamin D-deficient (serum $25(\mathrm{OH}) \mathrm{D}>25 \mathrm{nmol} / \mathrm{l})$ at baseline, per-protocol analyses were performed in which only participants with serum 25 $(\mathrm{OH}) \mathrm{D}<25 \mathrm{nmol} / 1$ at baseline were included. All analyses were based on two-sided tests with a two-sided $\alpha$ value of 0.05 .

\section{Results}

Recruitment and follow-up

The study sample included 232 persons who participated at baseline. Participants who did not provide a blood sample (or whose sample was insufficient, $n=17$ ), whose parents were both born in Europe $(n=2)$, or who did not answer the questionnaire at baseline $(n=1)$ were excluded. One person was excluded due to an exceptionally high serum $25(\mathrm{OH}) \mathrm{D}$ level 3 months after baseline $(25(\mathrm{OH}) \mathrm{D}=$ $240 \mathrm{nmol} / \mathrm{l})$. This resulted in the inclusion of data on 211 participants in the intention-to-treat analysis. The baseline serum $25(\mathrm{OH}) \mathrm{D}$ of 58 participants was above $25 \mathrm{nmol} / \mathrm{l}$. These subjects were included in the intention-to-treat, but excluded from the per-protocol, analyses. Figure 1 shows the flow of participants by type of analysis.

\section{Baseline characteristics}

The baseline characteristics of the 211 participants (53 men, 158 women) who were included in the intention-totreat analysis are shown in Table 1 . Their mean [SD] age was 41.3 [11.6] years and their average BMI was 28.7 [6.2] $\mathrm{kg} / \mathrm{m}^{2}$. Almost $33 \%$ of the participants were obese $\left(\geq 30 \mathrm{~kg} / \mathrm{m}^{2}\right)$. The baseline characteristics indicated a low social-economic status of the population studied: $63.8 \%$ had no paid job, and 53.4\% had achieved an education level of primary school or less. Their mean serum $25(\mathrm{OH})$ D was $22.5[11.1] \mathrm{nmol} / \mathrm{l}$ and $31(14.7 \%)$ had a serum 25 (OH)D of $12.5 \mathrm{nmol} / 1$ or less. Mean serum PTH was 9.6 [4.6] pmol/l, and 55 (26.1\%) had elevated levels of PTH (>11.0 pmol/1, upper reference limit), indicating certain secondary hyperparathyroidism. Mean serum alkaline phosphatase was $93 \mathrm{U} / 1$ when serum $25(\mathrm{OH}) \mathrm{D}$ was lower than $12.5 \mathrm{nmol} / 1$ and $73.5 \mathrm{U} / 1$ when serum $25(\mathrm{OH}) \mathrm{D}$ was 


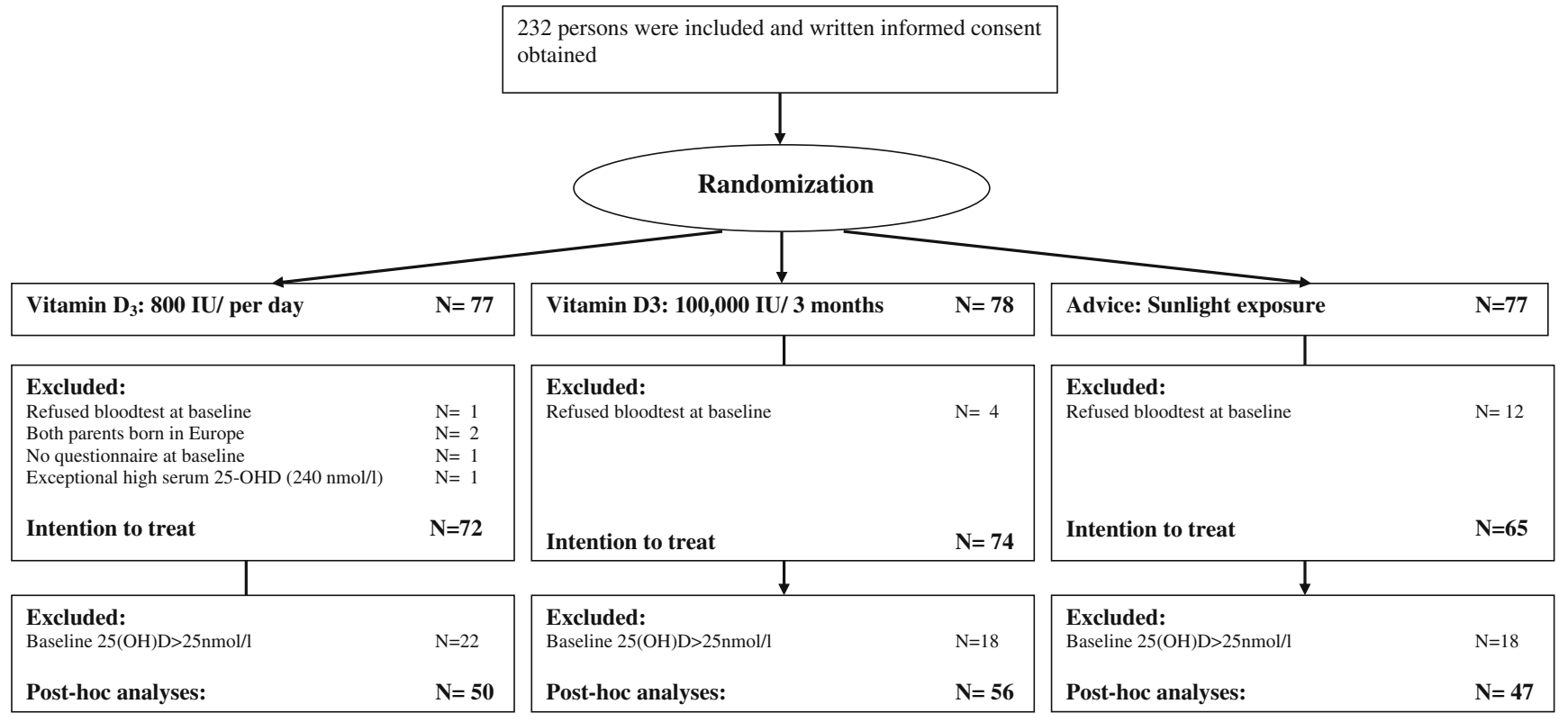

Fig. 1 Flow diagram of the participants in the study

higher than $25 \mathrm{nmol} / \mathrm{l}$. The three intervention groups were similar in demographic and prognostic variables, and baseline values of outcome measurements. However, as shown in Fig. 1, participants who did not provide a blood sample (or whose sample was insufficient) were more often randomized to the sunlight group ( $p=0.003$ ).

\section{Short-term intervention effects: intention-to-treat and per-protocol analyses}

\section{Sunlight exposure}

According to the questionnaire, the median time spent outside at baseline was $120 \mathrm{~min}$ in the three groups with no change after 3 months. Hands and face were exposed to sunlight in $98 \%$, and about $40-50 \%$ of the subjects exposed forearms to sunlight with no difference between the groups. The sunlight diary was not completed by the subjects with only two exceptions.

\section{Biochemistry}

Serum 25(OH)D level increased significantly in all intervention groups at 3 months after baseline compared to baseline level (Fig. 2). At both 3 and 6 months after baseline, the serum $25(\mathrm{OH}) \mathrm{D}$ concentrations were significantly higher in the supplementation groups than in the advised sunlight group. No significant differences were observed between the two supplementation groups. The proportion of participants with serum $25(\mathrm{OH}) \mathrm{D}<25,25-50$ and $50-75$ and $>75 \mathrm{nmol} / 1$ at different time points is shown in Table 2. With daily supplementation, serum 25(OH)D was higher than $50 \mathrm{nmol} / 1$ in $73.7 \%$ of the participants. Similar values were observed in $47.5 \%$ of the 100,000 IU group and $22 \%$ of the sunlight group. At 6 months, these percentages were lower than at 3 months. At 12 months, the percentage of participants with vitamin D deficiency (serum $25(\mathrm{OH}) \mathrm{D}<25 \mathrm{nmol} / \mathrm{l})$ was still lower than at baseline, except for the sunshine group. A significant interaction was observed between BMI and the increase of serum 25(OH)D after supplementation. The increase was larger in the 100,000 IU group when BMI was lower than $25 \mathrm{~kg} / \mathrm{m}^{2}$ (mean increase with $\mathrm{BMI}<25,25-30$, and $>30$ : 47,30 , and $21 \mathrm{nmol} / 1$, respectively). The power was too low for a stratified analysis.

Serum PTH concentrations decreased significantly in all three intervention groups at 3 months after baseline. At 6 months after baseline, PTH concentrations of both supplementation groups were still significantly lower compared to the sunlight group $(100,000 \mathrm{IU}, p=0.01$; $800 \mathrm{IU}, p=0.03)$. Per-protocol analyses showed the same pattern of serum $25(\mathrm{OH}) \mathrm{D}$ and PTH concentrations. However, at 3 months after baseline, a significant difference in increase of serum 25(OH)D was observed between both supplementation groups, in favor of the 800 IU group.

At baseline, alkaline phosphatase was increased above the upper reference level in 12 persons $(10 \%)$, which points to vitamin D-related bone disease (incipient or frank 
Table 1 Baseline characteristics of 211 participants, according to intervention, included in the intention-to-treat analysis

\begin{tabular}{|c|c|c|c|c|}
\hline & Total & Capsules 800IU & Capsules $100,000 \mathrm{IU}$ & Sunshine \\
\hline$N$ & $211(100)$ & $72(34.1)$ & $74(35.1)$ & $65(30.8)$ \\
\hline \multicolumn{5}{|l|}{ Gender $(n=211)$} \\
\hline Women & $158(74.9)$ & $54(34.2)$ & $55(34.8)$ & $49(31.0)$ \\
\hline Age (years) $(n=211)$ & $41.3 \pm 11.4$ & $40.5 \pm 10.8$ & $41.9 \pm 11.6$ & $41.5 \pm 12.0$ \\
\hline Body mass index $\left(\mathrm{kg} / \mathrm{m}^{2}\right)(n=211)$ & $28.7 \pm 6.2$ & $28.9 \pm 7.1$ & $28.5 \pm 6.0$ & $28.6 \pm 5.4$ \\
\hline$\geq 30$ : obese & $69(32.7)$ & $23(33.3)$ & $21(30.4)$ & $25(36.2)$ \\
\hline \multicolumn{5}{|l|}{ Ethnicity $(n=209)$} \\
\hline Turkish & $75(35.9)$ & $27(36.0)$ & $26(34.7)$ & $22(29.3)$ \\
\hline Moroccan & $61(29.2)$ & $17(27.9)$ & $23(37.7)$ & $21(33.4)$ \\
\hline Suriname/Dutch Antilles/Curacao & $33(15.8)$ & $16(48.5)$ & $10(30.3)$ & $7(21.2)$ \\
\hline African & $12(5.7)$ & $3(25.0)$ & $5(41.7)$ & $4(33.3)$ \\
\hline Asian & $28(13.4)$ & $8(28.6)$ & $10(35.7)$ & $10(35.7)$ \\
\hline \multicolumn{5}{|l|}{ Paid job $(n=210)$} \\
\hline No & $134(63.8)$ & $50(37.3)$ & $43(32.1)$ & $41(30.6)$ \\
\hline \multicolumn{5}{|l|}{ Education $(n=208)$} \\
\hline No or lower education & $111(53.4)$ & $35(31.5)$ & $40(36.0)$ & $36(32.4)$ \\
\hline Secondary school & $44(21.2)$ & $14(31.8)$ & $13(29.5)$ & $17(38.6)$ \\
\hline Higher education: College_-University & $53(25.5)$ & $23(43.4)$ & $20(37.7)$ & $10(18.9)$ \\
\hline \multicolumn{5}{|l|}{ Smoking $(n=210)$} \\
\hline Yes & $45(21.5)$ & $19(42.2)$ & $13(28.9)$ & $13(28.9)$ \\
\hline \multicolumn{5}{|l|}{ Drinking alcohol $(n=209)$} \\
\hline Yes & $33(15.8)$ & $13(39.4)$ & $13(39.4)$ & $7(21.2)$ \\
\hline $25(\mathrm{OH}) \mathrm{D}(\mathrm{nmol} / \mathrm{l})(n=211)$ & $22.45 \pm 11.1$ & $22.4 \pm 8.9$ & $21.8 \pm 12.3$ & $23.3 \pm 12.0$ \\
\hline PTH (pmol/1) $(n=210)$ & $9.6 \pm 4.6$ & $9.1 \pm 5.2$ & $10.1 \pm 4.4$ & $9.5 \pm 4.3$ \\
\hline Handgrip strength in $\operatorname{kgf}(n=210)$ & $32.8 \pm 9.9$ & $32.7 \pm 10.2$ & $32.0 \pm 9.7$ & $33.7 \pm 9.8$ \\
\hline Chairtest in seconds $(n=208)$ & $14.0 \pm 5.2$ & $13.8 \pm 4.4$ & $13.9 \pm 5.3$ & $14.3 \pm 5.8$ \\
\hline Functional limitations $(n=209)$ & $4.3 \pm 3.8$ & $4.7 \pm 3.8$ & $4.1 \pm 3.6$ & $4.2 \pm 4.0$ \\
\hline Headache episode per year $(n=209)$ & $114.6 \pm 129.0$ & $149.1 \pm 141.3$ & $74.8 \pm 98.1$ & $120.3 \pm 133.6$ \\
\hline
\end{tabular}

Values are numbers $(\%)$ or means \pm standard deviations $(\mathrm{SD})$

osteomalacia). After 6 months of treatment, alkaline phosphatase was increased in two persons $(2 \%)$ only. Serum alkaline phosphatase significantly decreased in all treatment groups. It decreased from 80 to $71 \mathrm{U} / 1$ after 6 months in the 800 IU group, from 81 to 71 in the 100,000 IU group, and from 75 to 68 in the sunlight group.

\section{Physical performance}

During the active treatment period, no between-group differences were observed in chair stand test and handgrip strength. Similarly, no within-group differences were observed over time.

Functional limitations

The three intervention groups reported significantly less difficulty in daily life activities at 3 months after baseline $(p<0.05)$; this was only borderline significant $(p=0.07)$ at 6 months after baseline. No between-group differences were observed. The number of participants without any functional limitations increased at 3 and 6 months compared to baseline in all three groups.

Pain

Six months after baseline, lower odds for pain in upper legs while sitting were observed compared to baseline. However, no between-group differences were observed. Perprotocol analysis showed no differences between groups or within groups. The studied population reported a high number of days per month with shoulder pain (approximately 15 times per month) and headache episodes (approximately 118 times per year). During treatment, no differences in shoulder pain were observed over time or between groups. Remarkably, only within the group of 
a
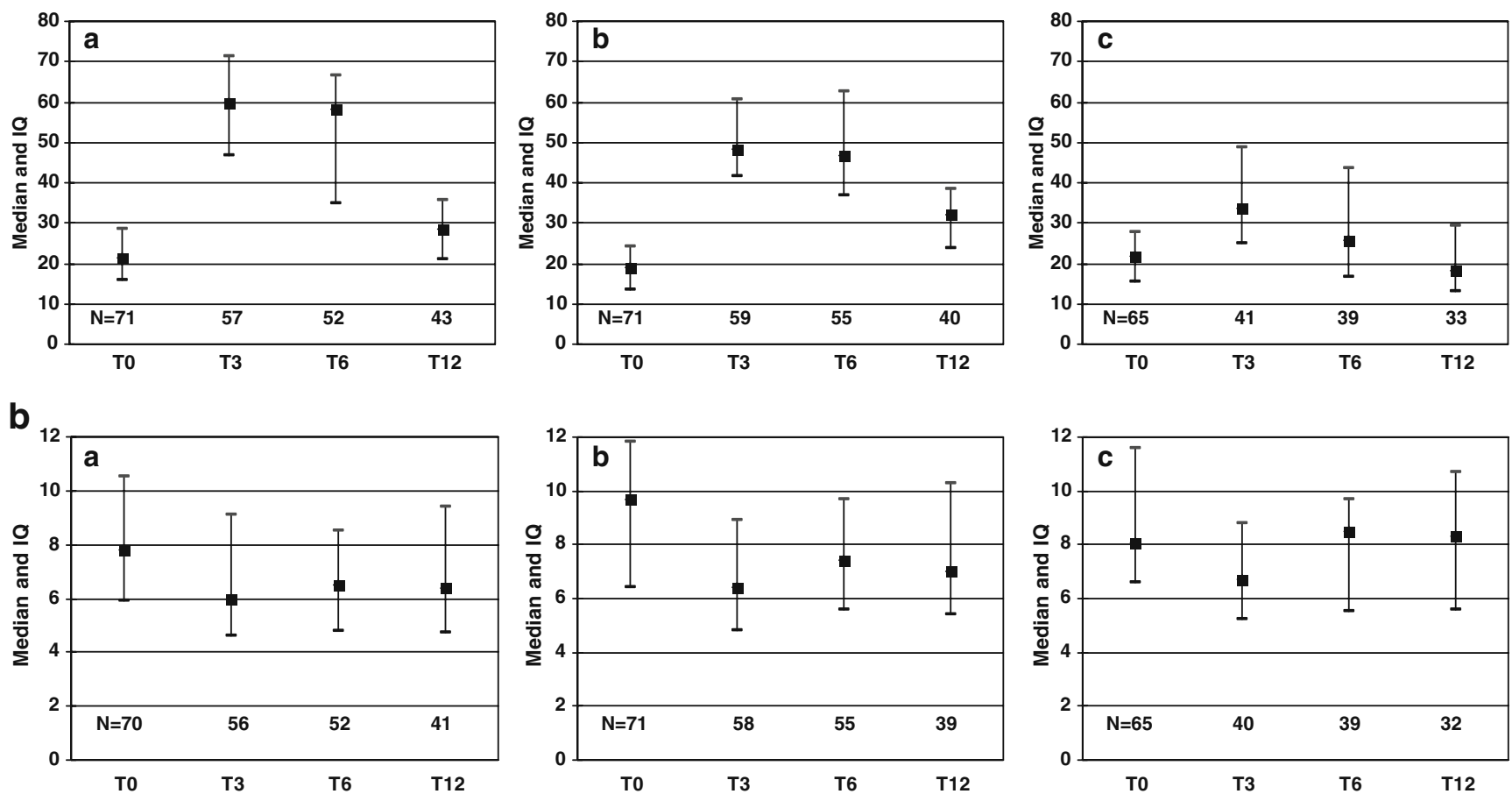

Fig. 2 a Serum 25(OH)D, nmol/1 (median, 25th-75th percentiles) in the $800 \mathrm{IU} /$ day group (A), the 100,000 IU/3 months group (B), and the sunlight group (C). b Serum PTH, pmol/1 (median, 25th-75th percentiles) in groups A, B, and C

800 IU per day did the number of headache episodes decrease significantly over time. Per-protocol analyses showed the same pattern.

Side effects

One side effect sometimes mentioned in the sunlight group was skin itching after sunlight exposure without visible changes. Side effects of the medication were not mentioned.

\section{Long-term intervention effects: intention-to-treat and per-protocol analyses}

Biochemistry

At 12 months after baseline, higher serum 25(OH)D concentrations were observed in the supplementation groups compared to the sunlight group (Fig. 2, Table 2). Within the sunlight group, serum $25(\mathrm{OH}) \mathrm{D}$ decreased to baseline level.

Table 2 Proportion (\%) of participants with serum $25(\mathrm{OH}) \mathrm{D}<25,25-50,50-75$, or $>75 \mathrm{nmol} / \mathrm{l}$ at baseline, 3,6 , and 12 months according to treatment group $800 \mathrm{IU} /$ day, 100,000 IU/3 months or sunshine exposure

\begin{tabular}{|c|c|c|c|c|c|c|c|c|c|}
\hline Group & Serum $25(\mathrm{OH}) \mathrm{D} \mathrm{nmol} / 1$ & $\mathrm{~T} 0 \%$ & $n$ & $\mathrm{~T} 3 \%$ & $n$ & $\mathrm{~T} 6 \%$ & $n$ & $\mathrm{~T} 12 \%$ & $n$ \\
\hline \multirow[t]{4}{*}{800 IU/day } & $<25$ & 66.2 & 47 & 7.1 & 4 & 11.5 & 6 & 37.2 & 16 \\
\hline & $25-50$ & 33.8 & 24 & 19.3 & 11 & 30.8 & 16 & 51.2 & 22 \\
\hline & $50-75$ & - & - & 52.6 & 30 & 40.4 & 21 & 7.0 & 3 \\
\hline & $>75$ & & - & 21.1 & 12 & 17.3 & 9 & 4.7 & 2 \\
\hline \multirow[t]{4}{*}{$100,000 \mathrm{IU} / 3$ months } & $<25$ & 76.0 & 54 & 1.7 & 1 & 7.3 & 4 & 27.5 & 11 \\
\hline & $25-50$ & 18.3 & 13 & 50.8 & 30 & 50.9 & 28 & 62.5 & 25 \\
\hline & $50-75$ & 5.6 & 4 & 39.0 & 23 & 34.5 & 19 & 10.0 & 4 \\
\hline & $>75$ & - & - & 8.5 & 5 & 7.3 & 4 & - & - \\
\hline \multirow[t]{4}{*}{ Advised sunlight exposure } & $<25$ & 69.2 & 45 & 24.4 & 10 & 48.8 & 19 & 72.7 & 24 \\
\hline & $25-50$ & 26.2 & 17 & 53.7 & 22 & 46.2 & 18 & 18.2 & 6 \\
\hline & $50-75$ & 4.6 & 3 & 19.5 & 8 & 5.1 & 2 & 6.1 & 2 \\
\hline & $>75$ & - & - & 2.4 & 1 & - & - & 3.0 & 1 \\
\hline
\end{tabular}

The treatment was provided for 6 months, from April/May till October/November 
Lower serum PTH concentrations were observed in supplementation groups compared to the advised sunlight intervention, which returned to baseline level. The difference was borderline significant for the $800 \mathrm{IU}$ group compared to the advised sunlight group $(p=0.065)$.

\section{Physical performance}

No differences were observed according to intention-totreat and per-protocol analyses in physical performance at 12 months after baseline compared to baseline, or between groups.

\section{Functional limitations}

According to intention-to-treat analyses, all groups reported less difficulty with daily life activities at 12 months after baseline, compared to baseline. However, no differences between interventions were observed.

\section{Pain}

Compared to baseline, at 12 months after baseline, no differences were observed in odds for pain in upper legs, days with shoulder pain, or number of headache episodes.

\section{Discussion}

As far as we know, this is the first randomized clinical trial in which the effect of advised sunlight exposure was compared with that of vitamin D supplementation. Sunlight exposure is the natural way to increase serum $25(\mathrm{OH}) \mathrm{D}$ concentrations, although the effects depend on the season and on the area of exposed skin.

In our study, vitamin $\mathrm{D}$ supplementation appeared to be necessary for adequate serum 25(OH)D concentrations when treating vitamin $\mathrm{D}$ deficiency in non-western immigrants living in the Netherlands. In the short term, serum 25(OH)D levels increased and serum PTH levels decreased in the advised sunlight group, but significant differences were observed between the effect of oral supplementation and sunlight exposure advice on both serum 25(OH)D and PTH concentrations. In the long term, serum 25(OH)D decreased and PTH levels again increased to baseline level within the sunlight group, while the supplementation groups were still better off at 12 months than at baseline.

Although Chel and colleagues have shown that ultraviolet irradiation is as effective as vitamin D supplementation in geriatric patients [31], exposure to sunlight itself was not very effective in our study. This may be explained by the pigmented skin of the study population, by limited skin exposure due to skin-covering clothes, and by limited sunlight exposure. According to The Norwegian Institute for Air Research, it takes 2.4 times longer for persons with dark skin (skin type 5) to synthesize the same amount of vitamin D than for persons with skin type 2 . For persons with skin type 6 , this will take four times longer. (http://nadir.nilu.no/ olaeng/fastrt/ VitD_quartMED.html). The skin surface exposed to sunlight can be estimated at $5 \%$ (face and hands) to $15 \%$ (face, forearms, and lower legs) in some individuals. Non-western immigrants usually expose themselves less to sunshine than born Dutch people due to cultural and religious habits. In fact, a poor vitamin D status can be seen in pigmented persons even in regions with abundant sunshine [32].

Although the participants received supplementation during 6 months, no further increase of serum 25(OH)D levels were observed after 3 months, and PTH levels started to increase after 3 months. This could indicate a problem with compliance. However, participants took 100,000 IU under supervision, and exactly the same pattern is observed in the $800 \mathrm{IU}$ group and the sunlight group. This may indicate that supplementation was inadequate. A dose-finding study in nursing home residents studied with the same $25(\mathrm{OH}) \mathrm{D}$ assays showed that serum $25(\mathrm{OH}) \mathrm{D}$ was higher than $50 \mathrm{nmol} / \mathrm{l}$ with vitamin $\mathrm{D}$ $600 \mathrm{IU} /$ day in $90 \%$ of the participants [33]. This fact and the decrease in serum 25(OH)D between 3 and 6 months (Fig. 2, Table 2) indicate a compliance problem. Another point of concern is the interaction of the increase of serum $25(\mathrm{OH}) \mathrm{D}$ after supplementation with BMI, mainly in the 100,000 IU group. Although this analysis should be considered exploratory, it may indicate that overweight and obese persons will need higher supplementation doses. The negative relationship between body fat percentage and serum 25(OH)D has been reported in the Longitudinal Aging Study Amsterdam [34].

It is striking that PTH concentrations decreased most in the 100,000 IU group, although serum 25(OH)D concentrations increased most in the $800 \mathrm{IU}$ group. This might be due to a higher peak concentration of serum PTH in the 100,000 IU group. The mean serum alkaline phosphatase decreased in all groups by about $20 \%$. The high alkaline phosphatase is a sign of high bone turnover or disturbed mineralization due to vitamin D deficiency. Besides serum 25(OH)D and PTH concentrations, several clinical outcomes were studied. An improvement in physical performance was not observed. Difficulties with daily life activities decreased significantly, but no differences were observed between the interventions. This may indicate that only a small improvement in vitamin D status is needed to improve functional limitations. Reported pain was not consistent over time or between interventions: number of days with headache episodes decreased significantly among participants in the 800-IU intervention and reported pain in upper legs improved significantly in the 100,000 -IU intervention compared to 
the advised sunlight intervention, but no improvement was observed in shoulder pain.

The inconsistent clinical results can be explained by the methodological restrictions of this study. There was no placebo-control group as this was judged unethical in this vitamin D-deficient population. Handgrip strength is known to be positively correlated with both lower-extremity and upper-body strength, and it appears to be a reliable test [35, 36]. The chair stand test is reliable and related to vitamin $D$ status [14], but both relationships have been established in older populations. The impact of vitamin D deficiency on muscle strength could be less in younger persons than in older persons. In addition, the tests could not be sufficiently discriminative in a younger population. The tests were conducted in 11 different centers by different observers, and this may also explain the lack of findings. A practical limitation of this study is that the diaries of sunlight exposure were poorly completed. Therefore, we only had a rough indication of sunlight exposure during the summer from questionnaires, but no measure of recent sun exposure.

Some remarkable results were found within the group of 800 IU per day: the number of headache episodes decreased significantly over time. Strangely, the same pattern was not observed in the $100,000-\mathrm{IU}$ intervention. A high number of days with headache episodes per year was reported previously in vitamin D-deficient non-western immigrants in the Netherlands [8], but as far as we know, no relation between vitamin $\mathrm{D}$ deficiency and headache has been observed before.

Attention should be paid to the combination of obesity and vitamin D deficiency. Almost 33\% of the studied population was obese $\left(\mathrm{BMI}>30 \mathrm{~kg} / \mathrm{m}^{2}\right)$. Obesity is associated with reduced serum $25(\mathrm{OH}) \mathrm{D}$ and increased serum PTH concentrations [34, 37]. In obesity, vitamin D production in the skin is not impaired, but after sun exposure, obese individuals only show half of the increase of serum 25(OH)D compared to non-obese individuals. It is suggested that the subcutaneous fat accumulation in obese people hampers the passage of vitamin $\mathrm{D}$ formed in the skin into the blood circulation. In addition, obese individuals have much lower surface-tovolume ratio than normal-weight people. As a result, the vitamin $\mathrm{D}$ produced in the skin is distributed over a larger volume and should not be expected to produce the same increment as in thinner individuals. Advice for sunlight exposure does not appear to be an effective intervention in obese people.

Besides the fact that sunlight was not very effective in our study, and the higher dropout of participants in the sunlight group ( $p=0.003$ ), it can be questioned whether an advice about sunlight exposure will be heard at all. When promoting sunlight exposure, the strong and widespread sun safety messages in the past few years should be taken into account. Vitamin D supplementation is necessary, but compliance may be a problem. Only $73 \%$ of 800 IU group and $47 \%$ of the 100,000 IU group reached a serum $25(\mathrm{OH})$ D level over $50 \mathrm{nmol} / 1$, while the level of $75 \mathrm{nmol} / 1$ was only reached by $21 \%$ of the 800 IU group. Therefore, the efficacy of food fortification should also be evaluated, e.g., fortification of milk and other dairy products, orange juice [38], bread [39], or vegetable oil.

Finally, the non-western immigrant population in the Netherlands is rapidly aging (the number of non-western immigrants of $65+$ years increased from 28,408 in 2000 to 57,242 in 2007 (http://statline.cbs.n1/StatWeb/start.asp, selection population to origin and generation, accessed 15 August 2007)). They are exposed to multiple risk factors (aging, lifestyle habits, skin pigmentation). Because of the fact that vitamin D deficiency has a negative influence on health, more effort should be spent on the early detection and treatment of people with suboptimal concentrations of vitamin D.

An important limitation of the study is that it was done in many practices with many observers, increasing the variation on clinical outcome measurements. A second limitation is the poor registration of sunshine exposure and the poor compliance with it.

In conclusion, the results of this randomized controlled trial show that vitamin D supplementation is much more effective than advice for sunlight exposure when treating vitamin $\mathrm{D}$ deficiency in non-western immigrants. The vitamin D dose of $800 \mathrm{IU} /$ day is not sufficient to increase serum $25(\mathrm{OH}) \mathrm{D}$ over $50 \mathrm{nmol} / 1$ in more than $90 \%$, which probably is due to non-compliance in this group. Higher doses may be needed in persons with higher BMI.

Acknowledgements We are grateful to all GPs for their collaboration, our colleagues from the Endocrine laboratory for their biochemical estimates, Leida van der Mark for her help in processing the data, and all interviewers for their help in collecting the data.

Author's Contribution ISW, AJPB, IMM, NMvS, and PL were involved in the study design; ISW, AJPB, IMM, and PL were involved in data collection; ISW, NMvS, and DLK analyzed the data; and all authors were involved in writing the manuscript.

Conflicts of interest None.

Open Access This article is distributed under the terms of the Creative Commons Attribution Noncommercial License which permits any noncommercial use, distribution, and reproduction in any medium, provided the original author(s) and source are credited.

\section{References}

1. Meyer HE, Falch JA, Sogaard AJ, Haug E (2004) Vitamin D deficiency and secondary hyperparathyroidism and the association with bone mineral density in persons with Pakistani and Norwegian background living in Oslo, Norway, The Oslo Health Study. Bone 35:412-417 
2. Swan CH, Cooke WT (1971) Nutritional osteomalacia in immigrants in an urban community. Lancet 2:356-359

3. Glerup H, Rytter L, Mortensen L, Nathan E (2004) Vitamin D deficiency among immigrant children in Denmark. Eur J Pediatr 163:272-273

4. Erkal MZ, Wilde J, Bilgin Y, Akinci A, Demir E, Bodeker RH, Mann M, Bretzel RG, Stracke H, Holick MF (2006) High prevalence of vitamin D deficiency, secondary hyperparathyroidism and generalized bone pain in Turkish immigrants in Germany: identification of risk factors. Osteoporos Int 17:1133-1140

5. Holvik K, Meyer HE, Haug E, Brunvand L (2005) Prevalence and predictors of vitamin D deficiency in five immigrant groups living in Oslo, Norway: the Oslo Immigrant Health Study. Eur J Clin Nutr 59:57-63

6. Mithal A, Wahl DA, Bonjour JP, Burckhardt P, Dawson-Hughes B, Eisman JA, El-Hajj Fuleihan G, Josse RG, Lips P, Morales-Torres J (2009) Global vitamin D status and determinants of hypovitaminosis D. Osteoporosis Int 20:1807-1820

7. Grootjans-Geerts I, Wielders JP (2002) A pilot study of hypovitaminosis D in apparently healthy, veiled, Turkish women: severe vitamin D deficiency in $82 \%$. Ned Tijdschr Geneeskd 146:1100-1101

8. Van der Meer IM, Boeke AJ, Lips P, Grootjans-Geerts I, Wuister JD, Devillé WL, Wielders JP, Bouter LM, Middelkoop BJ (2008) Fatty fish and supplements are the greatest modifiable contributors to hydroxyvitamin D concentration in a multi-ethnic population. Clin Endocrinol 68:466-472

9. Van der Meer I, Karamali NS, Boeke AJ, Lips P, Middelkoop BJ, Verhoeven I, Wuister JD (2006) High prevalence of vitamin D deficiency in pregnant non-Western women in The Hague, Netherlands. Am J Clin Nutr 84:350-353

10. Holick MF (1987) Photosynthesis of vitamin D in the skin: effect of environmental and life-style variables. Fed Proc 46:1876-1882

11. Harris SS, Dawson-Hughes B (1998) Seasonal changes in plasma 25-hydroxyvitamin D concentrations of young American black and white women. Am J Clin Nutr 67:1232-1236

12. Lips P (2001) Vitamin D deficiency and secondary hyperparathyroidism in the elderly: consequences for bone loss and fractures and therapeutic implications. Endocr Rev 22:477-501

13. Lips P (2006) Vitamin D physiology. Prog Biophys Mol Biol 92:4-8

14. Wicherts IS, van Schoor NM, Boeke AJ, Visser M, Deeg DJ, Smit J, Knol DL, Lips P (2007) Vitamin D status predicts physical performance and its decline in older persons. J Clin Endocrinol Metab 92:2058-2065

15. Bischoff-Ferrari HA, Dietrich T, Orav EJ, Hu FB, Zhang YQ, Karlson EW, Dawson-Hughes B (2004) Higher 25-hydroxyvitamin D concentrations are associated with better lower-extremity function in both active and inactive persons aged $>=60 \mathrm{y}$. Am J Clin Nutr 80:752-758

16. Dawson-Hughes B, Heaney RP, Holick MF, Lips P, Meunier PJ, Vieth R (2005) Estimates of optimal vitamin D status. Osteoporos Int 16:713-716

17. Dhesi JK, Bearne LM, Moniz C, Hurley MV, Jackson SHD, Swift CG, Allain TJ (2002) Neuromuscular and psychomotor function in elderly subjects who fall and the relationship with vitamin D status. J Bone Miner Res 17:891-897

18. Gerdhem P, Ringsberg K, Obrant K, Akesson K (2005) Association between 25-hydroxy vitamin D levels, physical activity, muscle strength and fractures in the prospective population-based OPRA Study of Elderly Women. Osteoporos Int 16:1425-1431

19. Pfeifer M, Begerow B, Minne HW, Schlotthauer T, Pospeschill M, Scholz M, Lazarescu AD, Pollahne W (2001) Vitamin D status, trunk muscle strength, body sway, falls, and fractures among 237 postmenopausal women with osteoporosis. Exp Clin Endocrinol Diab 109:87-92

20. Zamboni M, Zoico E, Tosoni P, Zivelonghi A, Bortolani A, Maggi S, Di Francesco V, Bosello O (2002) Relation between vitamin D, physical performance, and disability in elderly persons. J Gerontol Biol Sc Med Sc 57:M7-M11

21. Houston DK, Cesari M, Ferrucci L, Cherubini A, Maggio D, Bartali B, Johnson MA, Schwartz GG, Kritchevsky SB (2007) Association between vitamin D status and physical performance: the InCHIANTI study. J Gerontol A Biol Sci Med Sci 62:440-446

22. Mowe M, Haug E, Bohmer T (1999) Low serum calcidiol concentration in older adults with reduced muscular function. J Am Geriatr Soc 47:220-226

23. Plotnikoff GA, Quigley JM (2003) Prevalence of severe hypovitaminosis D in patients with persistent, nonspecific musculoskeletal pain. Mayo Clin Proc 78:1463-1470

24. Kenny AM, Biskup B, Robbins B, Marcella G, Burleson JA (2003) Effects of vitamin D supplementation on strength, physical function, and health perception in older, community-dwelling men. J Am Geriatr Soc 51:1762-1767

25. Verreault R, Semba RD, Volpato S, Ferrucci L, Fried LP, Guralnik JM (2002) Low serum vitamin D does not predict new disability or loss of muscle strength in older women. J Am Geriatr Soc 50:912-917

26. Stel VS, Smit JH, Pluijm SMF, Lips P (2003) Balance and mobility performance as treatable risk factors for recurrent falling in older persons. J Clin Epidemiol 56(7):659-668

27. Pluijm SMF, Tromp AM, Smit JH, Deeg DJH, Lips P (2000) Consequences of vertebral deformities in older men and women. J Bone Miner Res 15:1564-1572

28. Rasbash J, Steele F, Browne W, Prosser B (2005) A user's guide to MLwiN. Version 2.0. University of Bristol, Bristol

29. Maas CJM, Snijders TAB (2003) The multilevel approach to repeated measures for complete and incomplete data. Quality \& Quantity 71-89

30. Snijders TAB, Bosker RJ (1999) Multilevel analysis. An introduction to basic and advanced multilevel modeling. Sage, London

31. Chel VG, Ooms ME, Popp-Snijders C, Pavel S, Schothorst AA, Meulemans CC, Lips P (1998) Ultraviolet irradiation corrects vitamin $\mathrm{D}$ deficiency and suppresses secondary hyperparathyroidism in the elderly. J Bone Miner Res 13:1238-1242

32. Binkley N, Novotny R, Krueger D, Kawahara Y, Daida YG, Lensmeyer B, Hollis BW, Drezner MK (2007) Low vitamin D status despite abundant sun exposure. J Clin Endocrinol Metab 92:2130-2135

33. Chel V, Wijnhoven HA, Smit JH, Ooms ME, Lips P (2008) Efficacy of different doses and time intervals of oral vitamin D supplementation without calcium in elderly nursing home residents. Osteoporosis Int 19:663-671

34. Snijder MB, van Dam RM, Visser M, Deeg DJ, Dekker JM, Bouter LM, Seidell JC, Lips P (2005) Adiposity in relation to vitamin D status and parathyroid hormone levels: a population-based study in older men and women. J Clin Endocrinol Metab 90:4119-4123

35. Greig CA, Young A, Skelton DA, Pippet E, Butler FM, Mahmud SM (1994) Exercise studies with elderly volunteers. Age Ageing 23:185-189

36. Kallman DA, Plato CC, Tobin JD (1990) The role of muscle loss in the age-related decline of grip strength: cross-sectional and longitudinal perspectives. J Gerontol 45:M82-M88

37. Wortsman J, Matsuoka LY, Chen TC, Lu Z, Holick MF (2000) Decreased bioavailability of vitamin D in obesity. Am J Clin Nutr 72:690-693

38. Tangpricha V, Koutkia P, Rieke SM, Chen TC, Perez AA, Holick MF (2003) Fortification of orange juice with vitamin D: a novel approach for enhancing vitamin D nutritional health. Am J Clin Nutr 77:1478-1483

39. Natri AM, Salo P, Vikstedt T, Palssa A, Huttunen M, Karkkainen MU, Salovaara H, Piironen V, Jakobsen J, Lamberg-Allardt CJ (2006) Bread fortified with cholecalciferol increases the serum 25hydroxyvitamin D concentration in women as effectively as a cholecalciferol supplement. J Nutr 136:123-127 